\title{
STUDI TENTANG BENTUK SANGKAL BAHASA JEPANG
}

\section{Justien R.R.Wuisang}

Universitas Negeri Manado, Indonesia

Email: justienwuisang@unima.ac.id

\section{Abstract}

The form of denial of Japanese is basic mastery with a fairly high frequency of use. So Japanese learners must master the denial form. In Indonesian, the denial form does not have a big role in grammatical structure, but in Japanese it needs special attention and handling because it affects the change in the words it foloows, especially in verbs (dooshi 動詞) and adjectives (keiyooshi形容詞). The emphasis on mastery is more focused on the two types of denial that are mentioned later, namely-NAI and-MASEN because both of them have the highest frequency of use. This research uses descriptive method with literature study research techniques. So the research data is obtained from various book sources related to the form of refutation. While the type of data is in the form of sentences that contain both-nai and-masen forms of denial along with their explanations. The collected data are grouped and then described then concluded.

Keywords: denial, -nai, -masen

\begin{abstract}
Abstrak
Bentuk sangkal dalam Bahasa Jepang merupakan penguasaan dasar dengan frekuensi penggunaan yang cukup tinggi. Pembelajar bahasa Jepang wajib menguasai bentuk sangkal. Dalam bahasa Indonesia, bentuk sangkal tidak memiliki peranan yang besar dalam struktur gramatikal namun dalam bahasa Jepang hal ini perlu perhatian serta penanganan khusus karena berpengaruh terhadap perubahan kata yang diikutinya terlebih pada kata kerja (dooshi) dn kata sifat (keiyooshi). Titik berat penguasaan lebih diarahkan pada dua jenis bentuk sangkal yang disebutkan belakangan yakni -NAI dan-MASEN karena keduanya yang paling tinggi frekuensi penggunaannya. Penelitian ini menggunakan metode deskriptif dengan teknik penelitian studi kepustakaan. Jadi data penelitian diperoleh dari berbagai sumber buku yang berhubungan dengan bentuk sangkal. Sedangkan jenis datanya berupa kalimat-kalimat yang mengandung bentuk sangkal baik -masen maupun -nai beserta penjelasannya. Data yang terkumpul, dikelompokkan selanjutnya dijelaskan kemudian disimpulkan.
\end{abstract}

Kata Kunci: bentuk sangkal; -nai; -masen; Bahasa Jepang

\section{Pendahuluan}

Salah satu unsur bahasa Jepang yang termasuk dalam tatabahasa (Bunpo) adalah bentuk sangkal atau menyangkal (mizenkei) yang mempunyai arti tidak atau bukan.

How to cite:

E-ISSN:

Published by:
Wuisang, Justien R.R. (2021) Studi Tentang Bentuk Sangkal Bahasa Jepang. Syntax Literate. 6(5). http://dx.doi.org/10.36418/syntax-literate.v6i5.2736

2548-1398

Ridwan Institute 
Bentuk sangkal dapat mengikuti jenis kata kerja, kata sifat maupun kata benda. Bentuk sangkal bahasa Jepang terdiri atas beberapa jenis yaitu:

1. -ZU: Bentuk sangkal yang digolongkan sebagai kata kerja bantu negatif yang banyak digunakan dalam ragam bahasa tulis.

Contoh :
a.じしょを ひかずに 中国語の 新聞が 読めますか。

Apakah tanpa membuka kamus, dapat membaca bahasa Cina? (Nihongo shoho 1989:186)

b. 雨にも かかわらず、出かけました。

Tidak peduli hujan, setiap hari saya keluar.

c. 私を またず、先に行きなさい。

Jangan menunggu saya, pergilah lebih dahulu. (Chandra, 2009)

2. -NU: Bentuk sangkal kata kerja bantu negatif yang lazim dipakai oleh kaum tua. Contoh :
a. Ikanu
行かぬ Tidak pergi
b. Dekakenu
出かけぬ Tidak keluar
c. Wakaranu わからぬ Tidak menegrti (Chandra, 2009)

3. - MAI : Kata kerja bantu negatif yang menunjukkan tekad untuk tidak akan melakukan suatu hal dan menunjukkan suatu perkiraan atau dugaan sangkalan negatif.

Contoh :
a. このことは だれにもいうまい。

Saya tak akan mangatakan hal ini kepada siapapun.

b. たぶん そう では あるまい。

Barangkali bukan begitu.

4. -Nai : Bentuk sangkal yang biasanya dipakai sebagai bentuk biasa (futsu kei) dan dalam situasi yang informal.

Contoh :
a. みざわさん は 仕事がない。 Mizawa tidak ada pekerjaan.
b. 2. そこには 何も 書かないでください。
Disitu jangan ditulisi apapun.
c.きょうは あつく ないです。
Hari ini tidak panas. (Ogawa, 2000)

5. - Masen : Sama dengan -nai namun bentuk -masen biasanya dipakai dalam situasi formal.

Contoh :
a. わたしは 日本人 ではありません。

Saya bukan orang Jepang.

b. おとといは 雨は ふりませんでした。

Kemarin tidak turun hujan. (Ogawa, 2000)

Bentuk sangkal bahasa Jepang merupakan penguasaan dasar dengan frekuensi penggunaan yang cukup tinggi. Jadi wajar bila pembelajar bahasa Jepang wajib menguasai bentuk sangkal .Dalam buku-buku pelajaran bahasa Jepang, bentuk sangkal biasanya merupakan materi yang mengisi pelajaran-pelajaran awal. Misalnya Nihongo Shoho tahun 1989 pelajaran 1 dengan judul Watashi wa Nihonjin desu, unsure 
penjelasan tatabahasanya langsung menjelaskan tentang bentuk menyangkal dari desu yaitu dewa arimasen. Minna no Nihongo I pelajaran 1 juga memuat hal yang sama.Dengan demikian penguasaan bentuk sangkal merupakan salah satu kemampuan dasar bahasa Jepang.

Dalam bahasa Indonesia, bentuk sangkal tidak memiliki peranan yang besar dalam struktur gramatikal namun dalam bahasa Jepang hal ini perlu perhatian serta penanganan khusus karena berpengaruh terhadap perubahan kata yang diikutinya terlebih pada kata kerja (dooshi) dan kata sifat (keiyooshi). Titik berat penguasaan lebih diarahkan pada dua jenis bentuk sangkal yang disebutkan belakangan yakni -NAI dan MASEN karena keduanya yang paling tinggi frekuensi penggunaannya,disamping beberapa perbedaan prinsip, letak serta situasi yang kompleks diantara keduanya, menjadi makin menarik untuk diteliti.

Bentuk sangkal atau menyangkal -MASEN dan -NAI adalah "kata kerja bantu negatif atau menyangkal bagi kata sebelumnya" (Rohadi, 2003). Bentuk sangkal -masen dan -nai tidak dapat berdiri sendiri melainkan disambungkan pada kata kerja, kata sifat dan kata benda. Dengan kata lain kata kerja, kata sifat serta kata benda untuk bentuk negatifnya akan mengalami perubahan bentuk dengan menambahkan -masen atau -nai. -Masen dan -Nai sendiri disebut kata kerja bantu (jodoshi) yang mempunyai arti gramatikal tidak atau bukan. Jadi kata kerja, kata sifat serta kata benda yang tidak diikuti dengan -masen atau-nai bukan sebagai bentuk menyangkal.

\section{Metode Penelitian}

Penelitian ini menggunakan metode deskriptif dengan teknik penelitian studi kepustakaan. Jadi data penelitian diperoleh dari berbagai sumber buku yang berhubungan dengan bentuk sangkal. Sedangkan jenis datanya berupa kalimat-kalimat yang mengandung bentuk sangkal baik - masen maupun -nai beserta penjelasannya. Data yang terkumpul, dikelompokkan selanjutnya dijelaskan kemudian disimpulkan.

\section{Hasil dan Pembahasan}

Berdasarkan hasil penelitian, maka data berupa kalimat-kalimat bahasa Jepang yang mengandung bentuk sangkal-masen dan -nai adalah :

\section{A. -MASEN}

1. サントスさんは 学生じゃ ありません。

Santosusan wa gakusei ja arimasen.

Sdr. Santos bukan mahasiswa.

2. 三ラさんは 先生ですか。いいえ、先生じゃありません。

Mira san wa sensei desuka? Iie, sensei dewa arimasen.

Apakah Mira guru?. Bukan, dia bukan guru.

Minna no Nihongo I ,2002:16-17)

3. 私は ジャカルタへ 行きません。

Watashi wa Jekarta e ikimasen.

Saya tidak akan pergi ke Jakarta.

4. 父はへやに 新聞をよみません。

Chichi wa heyani shinbun wo yomimasen.

Ayah tidak membaca Koran di kamar. 
5. 今晚、父は うちへ帰りません。

Konban chichi wa uchi e kaerimasen.

Malam ini ayah tidak pulang rumah.

6. 人々は バスに のりません。

Hitobito wa basuni norimasen.

Orang-orang tidak naik bus.

7. 私の本は 小さくありません。

Watashi no hon wa chiisaku arimasen.

Buku saya bukan yang kecil.

8. この日本語の 新聞は 新しくありません。

Kono Nihongo no shinbun wa atarashiku arimasen.

Koran bahasa Jepang ini tidak baru (Rohadi, 2003).

9. 東京はしずかではありません。

Tokyo wa shizuka dewa arimasen.

Tokyo tidak sunyi (AOTS, 1992).

10.きのう 勉強しましたか。いいえ、勉強しませんでした。

Kino benkyou shimashitaka?Iie, benkyou shimasen deshita.

Apakah kemarin belajar? Tidak,kemarin saya tidak belajar (Ogawa, 2000).

11. それは わたしのくつでは ありません。

Sore wa watashi no kutsu dewa arimasen.

Itu bukan sepatu saya.

12. れいぞうこの 中にごはんも ありますか。

いいえ、ごはんは ありません。

Reizouko no naka ni gohan mo arimasuka?

Iie,gohan wa arimasen.

Apakah didalam lemari es ada juga nasi?

Tidak, tidak ada nasi

13.がくせいは どこかに いますか。

いいえ、がくせいは どこにもいません。

Gakusei wa dokoka ni imasuka.

Iie, gakusei wa dokonimo imasen.

Apakah ada mahasiswa di suatu tempat?

Tidak, dimanapun tidak ada mahasiswa (Suzuki, 1989; Tsuchikane, 2009).

14. 田中さんは 親切では ありません。

Tanakasan wa shinsetsu dewa arimasen.

Tuan Tanaka tidak ramah.

15. ワンさんは エンジニア では ありません。いしゃです。

Wang san wa enjinia dewa arimasen.Isha desu.

Tuan Wang bukan insinyur. Dia dokter..

16. わたしは フランス語を 勉強しませんでした。 
Watashi wa Furansugo wo benkyou shimasendeshita.

Saya tidak belajar bahasa Perancis.

17. 兄はさけを のみませんでした。

Ani wa sake wo nomimasendeshita.

Kakak saya tidak minum sake.

18.このかばんは 安くありませんでした。

Kono kaban wa yasuku arimasendeshita.

Tas ini tidak murah (JICA, 1994).

19. それは テレホンカードですか。

いいえ、そうじゃ ありません。

Sore wa terefonkaado desuka. Iie,soo ja arimasen.

Apakah itu kartu telefon? Bukan,itu bukan kartu telefon.

20.この かばんは あなたのですか。

いいえ、わたしのじやありません。

Kono kaban wa anata no desuka.

Iie, watashi no ja arimasen.

Apakah tas ini milik anda?

Bukan,Tas ini bukan milik saya.

21.きのう どこかへ 行きましたか。

いいえ、きのうどこへも いきませんでした。

Kinou, dokoka e ikimashitaka?

Iie, kinou dokoemo ikimasendeshita.

Apakah kemarin anda pergi?

Tidak, kemarin saya tidak pergi kemana-mana.

22.けさ 何か 食べましたか。何も食べませんでした。

Kesa nani ka tabemashitaka? Nanimo tabemasendeshita.

Tadi pagi kamu makan apa? Tidak makan apa apa.

23. 庭にだれかいますか。だれもいません。

Niwa ni dareka imasuka. Dare mo imasen.

Ada siapa di halaman? Tidak ada siapapun. (Ogawa, 2000)

24. 銀行は まだ 開いて いません。

Ginkou wa mada aite imasen.

Bank belum di buka.

25.レポートは もう 書きましたか。

いいえ、まだ書いていません。

Repooto wa mou kaite imasuka. Iie, mada kaite imasen.

Apakah anda sudah menulis laporan?

Belum, saya belum menulisnya.

(Ogawa, 2000)

26. さくら大学は あまり 有名な 大学 じゃありません。 
Sakura daigaku wa amari yumeina daigaku ja arimasen.

Universitas Sakura adalah universitas yang tidak begitu terkenal.

27. 英語があまり わかりません。

Eigo ga amari wakarimasen.

Saya tidak begitu mengerti bahasa Inggris.

28. 28 .お金が 全然ありません。

Okane ga zenzen arimasen.

Saya sama sekali tidak punya uang

29. 2 9.ここで たばこを 吸ってはいけません。禁煙ですから。

Koko de tabako wo sutte wa ikemasen. Kinen desu kara.

Tidak boleh merokok disini. Karena dilarang merokok.

30. 30 . 先生、ここで 遊んでもいいですか。

いいえ、いけません。

Sensei, koko de asondemo ii desuka. Iie, ikemasen.

Guru, apakah boleh bermain-main disini? .Tidak, tidak boleh.

31. 市役所の 電話番号をしていますか。

いいえ、しりません。

Shiyakusho no denwa bango wo shite imasuka.

Iie, shirimasen.

Apakah anda tahu nomor telefon kantor walikota.

Tidak, saya tidak tahu. (Ogawa, 2000)

32. アメリカ人は ひとりもいません。

Amerikajin wa hitori mo imasen.

Orang Amerika tidak ada seorangpun.

33. 冷蔵庫にたまごはひとつもありません。

Koko ni tamago wa hitotsu mo arimasen.

Di kulkas telur tidak ada sebutirpun.

(Suzuki, 1989)

Contoh-contoh kalimat dengan bentuk sangkal -masen berfungsi untuk menghaluskan bahasa atau kata-kata yang diucapkan. -Masen sebagai bentuk negative dari -masu merupakan verba bantu yang termasuk teinei.

Teineigo yaitu kata-kata atau bahasa yang diungkapkan untuk menghomati lawan bicara.

Kalimat-kalimat di atas dijelaskan sebagai berikut:

1. Kalimat-kalimat nomor $1,2,3,4,5,6,7,8,9,11,12,14,15,19,20,23-33$ menyatakan aksi masa kini ,akan datang atau kebiasaan. Perubahan pada kata kerja (dooshi) golongan I-III, kata sifat (keiyooshi) I dan II serta kata benda (meishi) telah diuraikan sebelumnya pada tinjauan pustaka.

2. Kalimat-kalimat nomor $10,16,17,18,21,22$ menunjukkan aksi masa lampau atau telah berlangsung. 
3. Bentuk sangkal-masen pada kalimat-kalimat nomor 2,10,12,13,19,20,21,22,23,30,31 merupakan jawaban negative (menyangkal) dari pertanyaan.Untuk menjawab kalimat tanya bahasa Jepang tanpa kata tanya (gimonshi misalnya ; doko=dimana, dare=siapa,ikura=berapa), maka bila setuju atau mengiyakan menggunakan hai=ya, dan bila menyangkal atau tidak setuju menggunakan Iie = tidak. Namun kadang-kadang lie tidak diucapkan lagi karena bentuk sangkal di belakang kalimat menunjukkan hal menyangkal. Lihat kalimat nomor 22,23 dan 24.

4. Kalimat sangkal -masen dengan kata tanya (gimonshi) yang langsung disusul dengan kata bantu (joshi) mo $\&$ dan kemudian diikuti dengan bentuk negative, maka kalimat tersebut bukanlah kalimat tanya melainkan menunjukkan kalimat negative mutlak. Seperti pada contoh kalimat nomor 13,21,22,23.

5. -Ja arimasen じゃありません adalah bentuk negative dari verba batu (jodoshi) desu です. Bentuk ini biasanya dipakai dalam percakapan sehari-hari. Dalam bahasa resmi seperti pidato, surat resmi ditulis dengan dewa arimasen ではあり ません. Seperti pada contoh kalimat nomor 1,2,19 dan 20.

6. Contoh kalimat nomor 24 dan 25 adalah kata bantu (joshi) mada yang diikuti oleh bentuk sangkal dari kata kerja -te iru ( sedang atau dalam keadaan) dengan bentuk sangkal -masen mempunyai arti negative yakni belum.

7. Kata keterangan (fukushi) amari あまり dan zenzen 全然 selalu diikuti oleh bentuk negative atau menyangkal , maka amari + bentuk sangkal kata kerja dan kata sifat berarti $=$ tidak begitu...., sedangkan zenzen+bentuk sangkal kata kerja dan kata sifat berarti $=$ sama sekali tidak.....Contoh kalimat nomor 26,27,28.

8. Kalimat nomor 29 dan 30 dengan ungkapan -te wa ikemasen 一て はけ ません menunjukkan arti larangan untuk menjawab penolakkan pemberian ijin yang kuat dengan kalimat -te mo ii desuka 一てもいいですか adalah dengan ungkapan Iie,ikemasen いいえ、いけません= tidak,tidak boleh. Namun ungkapan initidak dipakai kepada orang yang kedudukannya/derajatnya lebih tinggi atau lebih tua dari si pembicara.

9. Shirimasen しりません adalah bentuk negative dari shite imasu しています yang artinya tahu. Jadi menjawab tidak tahu ialah dengan shirimasen 知りませ ん bukan shite imasen していません. Contoh kalimat nomor 31.

10. Hitori mo dan hitotsu mo selalu diikuti dengan bentuk negative. Hitori mo+ imasen $=$ seorangpun tidak ada, hitotsu mo arimasen $=$ sebuahpun tidak ada.Contoh kalimat nomor 32 dan 33.

11. Contoh-contoh kalimat berikut ialah kalimat-kalimat yang menggunakan bentuk sangkal namun bukan berarti menyangkal. Seperti kata keterangan shika yang selalu diikuti oleh bentuk negatif atau menyangkal namun berarti =hanya.

$$
\text { 女の子は 三人 しかいません。 }
$$

Onna no ko wa sannin shika imasen. 
Anak perempuan hanya ada 3 orang.

$$
\text { ここに みかんは 三つしかありません。 }
$$

Koko ni mikan wa mitsu shika arimasen.

Disini hanya ada tiga buah jeruk

12. Kata kerja bentuk - masenka merupakan ungkapan bentuk negative namun bukan berate negative atau menayangkal melainkan ungkapan untuk mengajak dengan menanyakan pikiran lawan bicara. Bentuk kk+masenka menunjukkan rasa hormat kepada lawan bicara lebih dari ajakan dengan kk+mashoo.

$$
\begin{aligned}
& \text { いっしょに 京都へ 行きませんか。 } \\
& \text { Isshoni Kyoto e ikimasenka. } \\
& \text { Maukah kita pergi ke Kyoto bersama-sama? } \\
& \text { いっしょに 昼ごはんを 食べませんか。 } \\
& \text { Isshoni hirugohan wo tabemasenka. } \\
& \text { Bagaimana kalau kita makan siang bersama-sama? }
\end{aligned}
$$

B. -NAI

1.みざわさんは しごとが ない。

Mizawasan wa shigoto ga nai.

Mizawa tidak ada pekerjaan.

2.わたしは ジャカルタへ 行かない。

Watashi wa Jakarta e ikanai.

Saya tidak pergi ke Jakarta.

3. 私はこのものが 気にいらない。

Watashi wa kono mono ga ki ni iranai.

Saya tidak tertarik dengan barang ini.

4. けいことが ついていない。

Keikoutoga tsuite inai.

Lampu neon tidak dinyalakan.

(Chandra,1993:104-105)

5. 私は 日本語がやさしくない。

Watashi wa Nihongo ga yasashikunai.

Bagi saya bahasa Jepang tidak mudah.

6. この辞書は よくない。

Kono jisho wa yokunai.

Kamus ini tidak bagus.

(Aots, 1992:21,43)

7. そんな 事を ふしぎでわない。

Sonna koto wo fushigi dewa nai.

Hal semacam itu tidak heran. 
8. あの二人の結婚は 幸せではない。

Ano futari no kekkon wa shiawase dewanai.

Pernikahan kedua orang itu tidak bahagia.

9.これは 日本製の 歯ブラシではない。

Kore wa Nihonsei no ha burashi dewanai.

Ini bukan sikat gigi buatan Jepang.

10.ここはようちえん ではない。

Koko wa youchien dewanai.

Disini bukan taman kanak-kanak.

11.きのしたさんは えらい人 ではない。

Kinoshita san wa erai hito dewanai.

Dulunya Kinoshita bukan orang besar.

12. 始めは 日本しゅうかんになれなかった。

Hajime wa Nihon shuukan ni narenakatta.

Mula-mula saya tidak terbiasa dengan kebiasaan Jepang.

13.ゆべしみずさんはりょうにもどらなかった。

Yube, Shimizu san wa ryoo ni modoranakatta.

Tadi malam Shimizu tidak kembali ke asrama.

14. 私は森田さんの せいこがちよっとうらやましくなかった。

Watashi wa Morita san no Seiko ga chotto urayamashikunakatta.

Saya sedikitpun tidak irihati akan kesuksesan Morita.

15. 長い間 雨が 降らなくて、この葉が かれました。

Nagai aida ame ga furanakute, kono ha ga karemashita.

Karena lama tidak turun hujan, daun-daun menjadi kering.

16. 私の うちは 大きくなくて、部屋が二つあります。

Watashi no uchi wa ookikunakute, heya ga futatsu arimasu.

Rumah saya tidak besar, hanya ada 2 kamar.

17. 母も 元気ではなくて、父ももう年おとりました。

Haha mo genki dewanakute, chichi mo mou toshi otorimashita.

Ibuku tidak sehat, ayahpun sudah lanjut usia.

18. 私のとなり は 日本人ではなくて、韓国人です。

Watashi no tonari wa Nihonjin dewanakute, kankokujin desu.

Tetangga saya bukan orang Jepang melainkan orang Korea.

19. 写真を 撮らないでください。

Shashin wo toranaide kudasai.

Harap jangan memotret.

20. お酒を のまないでください。

Osake wo nomanaide kudasai.

Jangan minum sake.

21.あそこへ 来ないで下さい。 
Asoko e konaide kudasai.

Jangan datang kesana.

22.きょうかしょを 見ないで下さい。

Kyoukasho wo minaide kudasai.

Tolong jangan melihat buku catatan.

23. 電話番号を 忘れないでください。

Denwa bango wo wasurenaide kudasai.

Jangan lupa nomor telepon.

24. 私は 元気ですから、心配しないでください。

Watashi wa genki desukara, shinpai shinaide kudasai.

Karena saya sehat, jangan khawatir.

25. ここで かみくずを 捨てないでください。

Koko de kamikuzu wo sutenaide kudasai.

Jangan membuang sobekan kertas disini.

26. 荷物は ここに 置かないでください。

Nimotsu wa koko ni okanaide kudasai.

Barang jangan letakkan disini.

27. ゆりさんに 会わなくても いいです。

Yurikosan ni awanakute mo ii desu.

Tidak usah menemui Yuriko.

28. 先生と一緒に 行かなくてもいいです。

Sensei to isshoni ikanakute mo ii desu.

Tidak usah pergi bersama guru.

29. パスポートを 見せなくても いいです。

Pasupooto wo misenakute mo ii desu.

Tidak perlu menunjukkan paspor.

30. あした 来なくてもいいです。

Ashita konakute mo ii desu.

Besok tidak usah datang.

(Rohadi, 2003:80)

31. 自動車は ガソリンが なければ、走ることができない。

Jidousha wa gasorin ga nakereba, hashiro koto ga dekinai.

Kalau mobil tidak ada bensin, tidak bisa berjalan.

32.うきに なければ、すずしくならない。

Uki ni nakereba, suzushikunaranai.

Kalau sampai tidak musim hujan, tidak akan menjadi sejuk.

33.おからなければ、この 説明書をよんでください。

Wakaranakereba, kono setsumeisho wo yonde kudasai.

Kalau tidak mengerti, baca buku panduan ini.

(Chandra, 1993:109,110) 
34.ほかに 意見が なければ、これで 終わりましょう

Hoka ni iken ga nakereba, kore de owarimashoo.

Kalau tidak ada pendapat yang lain, kita akhiri sampai disini.

35. 時間が なければ、テレビを 見ません。

Jikan ga nakereba, terebi wo mimasen.

Kalau tidak ada waktu saya tidak menonton TV.

(Minna no Nihongo 2,2002:62,63)

36. 三ラさんは このニュースを 知っていますか。

いいえ、たぶん 知らないと 思います。

Mira san wa kono nyuusu wo shitte imasuka?

Iie, tabun shiranai to omoimasu.

Apakah sdr.Miller sudah tahu berita ini?

Tidak, saya kira mungkin dia belum tahu.

37. 山田さんは このことを たぶん 知らないと 思います。

Yamada san wa kono koto wo tabun shiranai to omoimasu.

Saya kira Yamada mungkin belum tahu hal ini.

(Minna no Nihongo 2, 2002:45)

38. 使い方が わからない とき、わたしに 聞いて ください。

Tsukaikata ga wakaranai toki, watashi ni kite kudasai.

Pada waktu anda tidak mengerti, silakan Tanya pada saya.

(Minna no Nihongo 1,2002:148)

39.しょうゆを つけないで 食べます。

Shooyu wo tsukenaide tabemasu.

Saya makan ini tanpa kecap asin Jepang.

40. 日曜日はどこも 行かないで、うちで ゆっくり 休みます。

Nichiyoubi wa dokomo ikanaide, uchi de yukkuri yasumimasu.

Pada hari minggu saya bersantai di rumah dan tidak pergi ke mana。

(Minna no Nihongo 2,2002:57)

41. 約束の 時間に 間に合わないかも しれません。

Yakusoku no jikan ni maniawanai kamo shiremasen.

Mungkin saya tidak dapat datang sesuai waktu yang disepakati.

42. もしかしたら 3 月に 卒業できないかもしれません。

Moshikashitara sangatsuni sotsugyou dekinai kamo shiremasen.

Kemungkinannya saya tidak dapat lulus pada bulan Maret.

(Minna no Nihongo 2,2002:44,45)

43. 年を 取ると、小さい 字が読めなくなります。

Toshi wo toru to,chiisai jig a yomenakunarimasu.

Kalau sudah tua tidak akan dapat membaca huruf kecil.

44.太りましたから、好きな 服が着られなくなりました。

Futorimashita kara,sukina fuku ga kirarenaku narimashita. 
Karena sudah gemuk,saya tidak dapat memakai baju yang saya sukai.

45. 歯に 悪いですから、甘い物を 食べないようにしています。

Ha ni warui desu kara, amai mono wo tabenaiyouni shite imasu.

Karena tidak baik untuk gigi, saya tidak makan makanan yang manis.

46. あしたは 絶対に 時間に 遅れないようにして ください。

Ashita wa zettai ni jikan ni okurenaiyouni shite kudasai.

Saya harap besok anda sama sekali tidak terlambat

Bentuk sangkal -nai berfungsi sebagai verba bantu yang dibuat dengan menggunakan konjugasi pertama (mizenkei). -Nai merupakan bentuk informal yang biasanya dipakai oleh orang yang akrab hubungannya atau kepada orang yang lebih rendah derajatnya/ lebih muda usianya.

Kalimat-kalimat dengan bentuk sangkal -nai dapat dijelaskan demikian:

1. Kalimat nomor 37 sampai 47 merupakan ungkapan untuk aksi masa kini,masa datang atau kebiasaan. Perubahan pada kata kerja (dooshi) golongan I -III, kata sifat (keiyooshi) golongan I dan II serta kata benda (meishi) seperti yang telah diuraikan pada tinjauan pustaka. Namun ada beberapa catatan yang diluar aturan perubahan yaitu :

KK. aru bukan berubah aranai melainkan "nai".

KK. iru bukan berubah iranai melainkan "inai".

KK.kau bukan berubah kaanai melainkan "kawanai" (selipkan konsonan w untuk semua kk yang berakhiran -u)

KS. ii bukan ikunai melainkan yokunai.

2. Kalimat nomor 48,49 dan 50 merupakan bentuk sangkal negative lampau.

Akhiran -i pada -nai diganti ku +nakatta.

3. Kalimat nomor 51 sampai 54 merupakan bentuk sambung dari bentuk sangkal nai yakni -nakute yang berfungsi menghubungkan dua kalimat atau lebih. Meskipun bentuk-te, namun tetap berfungsi sebagai bentuk sangkal yang berarti "tidak".

4. Kalimat nomor 55 sampai nomor 62 dengan pola V-naide kudasai merupakan pola negative dari bentuk permintaan v-te kudasai. V-naide kudasai bererti memohon atau meminta untuk tidak melakukan sesuatu hal atau pekerjaan.

5. Kalimat nomor 63 sampai nomor 66 merupakan kalimat menyangkal dari kalimat mengijinkan v-te mo ii. Kalimat ini manyatakan negative dan berarti "tidak usah"/"tidak perlu".

6. Kalimat nomor 67 sampai nomor 71 merupakan kalimat persyaratan. Nakereba adalah bentuk sangkal dari -ba. Nakereba dapat diartikan " kalau tidak....", atau "kalau bukan...".

7. Kalimat nomor 72 dan 73 merupakan kalimat perkiraan negative dengan pernyataan dugaan yang tingkat kepastiannya rendah. Kalimat biasa sebelum kata bantu (joushi) "to" dijadikan bentuk negative dan berarti "barangkali belum". 
8. -Nai pada kalimat nomor 74 sebagai bentuk sangkal yang dihubungkan dengan "toki" mempunyai arti " pada waktu tidak...."

9. Kalimat nomor 75 "V+naide" berarti "tanpa" sedangkan nomor 76 berarti "tidak". KK 1 merupakan perbuatan atau keadaan dalam KK2.

10. Kalimat nomor 77 dan 78, V-nai kamo shiremasen, menunjukkan dugaan pembicara terhadap kemungkinan terjadinya suatu kejadian.

11. Kalimat nomor 79 dan $80 \mathrm{v}$-naku narimasen, kk merupakan kk potensial (kanoo doushi) dimana keadaan berubah dan keadaan sebelumnya menghilang.

12. Kalimat nomor 81 yaitu v-nai youni shite imasu menunjukkan usaha seseorang melakukan suatu perbuatan dengan kesungguhan hati sebagai suatu kebiasaan yang berkelanjutan. Sedangkan nomor 82 v-nai youni shite kudasai merupakan permohonan sopan untuk hal yang hanya akan dilakukan satu kali saja.

13. Contoh-contoh kalimat berikut adalah -nai yang bukan berarti menyangkal.

もう帰らないといけません。

Mou kaeranai to ikemasen.

Saya harus pulang sekarang.

薬を 飲まなければなりません。

Kusuri wo nomanakereba narimasen.

Harus minum obat.

土曜日までに 本を 返さなければ なりません。

Doyoubi madeni hon wo kaesanakereba narimasen.

Harus mengembalikan buku paling lambat sebelum hari Sabtu.

(Ogawa, 2000)

\section{Kesimpulan}

Sebagai bentuk sangkal -nai dan - masen mempunyai arti yang sama yakni 'tidak' atau 'bukan' dan keduanya merupakan sangkalan bagi kata sebelumnya. Atau dengan kata lain sebagai bentuk negative dari bentuk positif. Selain itu persamaan keduanya ialah berkonsekuensi pada perubahan kata yaitu pada kata kerja(dooshi), kata sifat (keiyooshi) dan kata benda (meishi) serta mempunyai bentuk negative lampau.

Dapat diketahui pula beberapa perbedaan dari keduanya; -nai biasanya digunakan pada situasi informal (hubungan yang akrab, sesama teman, keluarga atau atasan kepada bawahan) sedangkan -masen cenderung pada situasi formal (pidato, bahasa tulis resmi ) atau bahasa 'teinei' yaitu bahasa atau kata-kata yang digunakan untuk menghormati lawan bicara .

Perbedaaa lainnya terletak pada posisi/letaknya; -masen selalu pada posisi akhir kalimat, sedangkan -nai dapat pada posisi lainnya serta lebih kaya dengan fungsi lainnya dalam kalimat seperti pada contoh:

1. Sebagai bentuk sambung;

Contoh: 長い間 雨が 降らなくて、木の葉が かれました。

Nagai aida ame ga furanakute,ki no ha ga karemashita.

Karena lama tidak turun hujan, daun-daun menjadi kering.

2. Menyatakan persyaratan;

Contoh: 自動車は ガソリンが なければ、走ることができない。 
Jidousha wa gasorin ga nakereba, hashiru koto ga dekinai,

Kalau mobil tidak ada bensin, tidak bisa berjalan.

3. Menyatakan tidak usah atau tidak perlu;

Contoh: パスポートを 見せなくても いいです。

Pasupooto wo misenakute mo ii desu.

Tidak usah menunjukkan paspor.

4. Menyatakan larangan;

Contoh: 写真を 撮らないでください。

Shashin wo toranaide kudasai.

Harap jangan memotret.

Untuk dapat meminimalisir kesulitan penggunaan kedua bentuk sangkal ini, hendaknya ditanamkan dulu perubahan dasar (katsuyoo) terutama untuk kata kerja(doushi) dan kata sifat (keiyooshi) disertai dengan porsi latihan sebanyak mungkin teristimewa pada mata kuliah yang berkaitan erat dengan tatabahasa seperti Bunpo (文 法), Nihongo（日本語, Sakubun（作文） 


\section{BIBLIOGRAFI}

AOTS. (1992). Shin Nihongo No Kiso I. Japan.

Arikunto,Suharsimi. 1983. Prosedur Penelitian, Suatu Pendekatan Praktik. Jakarta; Bina Pustaka. Google Scholar

Chandra, T. (2009). Nihongo No Joshi. Jakarta: Evergreen Japanese Course. Google Scholar

Chino, Naoko.2001. Partikel Penting Bahasa Jepang.Jakarta; Kesaint Blance Google Scholar

JICA. (1994). Catatan Tata Bahasa Jepang. Jakarta.

Minna no Nihongo I. 2002. Terjemahan dan Keterangan Tatabahasa I . Jakarta : Pustaka Lintas Budaya. Google Scholar

Minna no Nihongo II, 2002. Terjemahan dan Keterangan Tatabahasa II. Jakarta: Pustaka Lintas Budaya.

Ogawa, Iwao. (2000). Minna No Nihongo I \& II: Terjemahan dan Keterangan Tata Bahasa. Tokyo: 3A Corporation. Google Scholar

Pora, Muchlis. (2003).Konjugasi kata kerja Bahasa Jepang. Bekasi: Oriental

Rohadi. (2003). Bentuk Ungkapan dari Kata Sifat dan Kata Kerja. Jakarta: Oriental.

Samsuri. (1994). Gramatika Bahasa Jepang Modern Seri B. Jakarta:Dian Rakyat.

Sugihartono. 2001. Nihongo No Joshi. Bandung : Humaniora Google Scholar

Suzuki, Shinobu. (1989). Nihongo Shoho. Tokyo: Kokusai Koryuu Kikin. Google Scholar

Taniguchi,Goro. 1997. Kamus Standar Bahasa Jepang - Indonesia. Jakarta : Dian rakyat. Google Scholar

Tsuchikane, Yasuko. (2009). Dômoto Inshô (1891-1975) and Buddhist temple art in 20 th century Japan. Columbia University. Google Scholar

Yoshida,Yasuo. 2001. Bahasa Jepang Untuk Pemula (Japanese For Beginners). Jakarta: Harmony.

Copyright holder :

Justien R.R.Wuisang (2021) 
First publication right :

Journal Syntax Literate

This article is licensed under:

(cc) $(i)$ 